\title{
Peanut sensitization in a group of allergic Egyptian children
}

Elham Hossny ${ }^{1 *}$, Ghada Gad ${ }^{1}$, Abeer Shehab ${ }^{2}$ and Amgad El-Haddad ${ }^{3}$

\begin{abstract}
Background: There are no published data on peanut sensitization in Egypt and the problem of peanut allergy seems underestimated. We sought to screen for peanut sensitization in a group of atopic Egyptian children in relation to their phenotypic manifestations.

Methods: We consecutively enrolled 100 allergic children; 2-10 years old (mean $6.5 \mathrm{yr}$ ). The study measurements included clinical evaluation for site of allergy, possible precipitating factors, consumption of peanuts (starting age and last consumption), duration of breast feeding, current treatment, and family history of allergy as well as skin prick testing with a commercial peanut extract, and serum peanut specific and total IgE estimation. Children who were found sensitized to peanuts were subjected to an open oral peanut challenge test taking all necessary precautions.
\end{abstract}

Results: Seven subjects (7\%) were sensitized and three out of six of them had positive oral challenge denoting allergy to peanuts. The sensitization rates did not vary significantly with gender, age, family history of allergy, breast feeding duration, clinical form of allergy, serum total $\lg E$, or absolute eosinophil count. All peanut sensitive subjects had skin with or without respiratory allergy.

Conclusions: Peanut allergy does not seem to be rare in atopic children in Egypt. Skin prick and specific lgE testing are effective screening tools to determine candidates for peanut oral challenging. Wider scale multicenter population-based studies are needed to assess the prevalence of peanut allergy and its clinical correlates in our country.

\section{Introduction}

The prevalence of peanut allergy is not sufficiently studied in many developing countries including Egypt. Peanut allergy was estimated to affect $0.8 \%$ of children and $0.6 \%$ of adults in the US, showing a twofold increase over a 5 -year period [1,2]. A recent 11 year follow up survey showed that the prevalence of peanut allergy in children in the US in 2008 was $1.4 \%$ compared to $0.8 \%$ in 2002 and $0.4 \%$ in 1997 [3]. In the United Kingdom, the total estimate for clinical peanut allergy was $1.5 \%$ of 3-4 year-old children [4]. Relevant studies estimated the prevalence of peanut allergy to be $1.34 \%$ among primary school children in a Canadian province [5] and $1.15 \%$ among 3 year olds in the Australian capital territory with a trend for rise in prevalence between

\footnotetext{
* Correspondence: elham.hossny@gmail.com

'Departments of Pediatrics, Ain Shams University, Ramses Street, Cairo 11566, Egypt

Full list of author information is available at the end of the article
}

1997 and 2005 [6]. Peanut was the third most common sensitizing allergen in an Asian community especially in young atopic children with multiple food hypersensitivities and a family history of atopic dermatitis [7].

Studies to address the reasons for increased prevalence and persistence of food allergies, focusing primarily on peanut, have included the hygiene hypothesis; changes in the components of the diet, including antioxidants, fats, and nutrients, such as vitamin D; the use of antacids, resulting in exposure to more intact protein; food processing, such as for peanut roasting and emulsification to produce peanut butter compared with fried or boiled peanut; and extensive delay of oral exposure, thus increasing topical (possibly sensitizing) rather than oral (possibly tolerizing) exposure to food allergens $[8,9]$.

The evaluation of a child with suspected allergy to peanut should include a careful history taking, skinprick testing (SPT), measurement of serum-specific
C Biomed Central

C 2011 Hossny et al; licensee BioMed Central Ltd. This is an Open Access article distributed under the terms of the Creative Commons Attribution License (http://creativecommons.org/licenses/by/2.0), which permits unrestricted use, distribution, and reproduction in any medium, provided the original work is properly cited. 
IgE, and, confirmation by an oral food challenge $[10,11]$. The prevalence of confirmed food allergy based on confirmatory tests is lower than perceived allergy which is based on self report [12,13]. Diagnostic cut-off values for SPT and specific IgE results have improved the diagnosis of food allergy and thereby reduced the need to perform oral food challenges [14]. Overall, a negative peanut SPT has a negative predictive value of more than 95\% [15]. The positive predictive value, however, is significantly lower, reaching only $60 \%$ in patients with a convincing history of an allergic reaction [16]. Published values on positive SPT and specific IgE values vary from one series to another depending on several factors [12,17-20]. Cut-off values do not always have general acceptability and sometimes need to be individualized in the context of clinical impression [21].

There is an impression that peanut allergy is uncommon in Egypt and there are no published data on its incidence or prevalence. We sought to investigate the frequency of peanut sensitization and allergy in a group of atopic Egyptian infants and children in a pilot attempt to uncover its importance as an allergen in our country.

\section{Methods}

\section{Study Population}

This cross sectional study comprised 100 children diagnosed to have allergic diseases. They were enrolled consecutively after getting informed oral consent was obtained from the parents or care-givers. The study protocol gained approval from the local ethics committee.

Inclusion criteria:

- Age at enrollment between one and 18 years.

- A physician made diagnosis of allergic diseases including asthma, allergic rhinitis, urticaria, and eczema.

Exclusion criteria:

- Patients who cannot stop antihistamine therapy.

- Extensive skin lesions, scars, positive dermatographism, and very dark skin.

- Treatment with systemic corticosteroids for more than 7 days.

- Other chronic or debilitating illness.

\section{Study Measurements}

All patients included in the study were subjected to the following:

\section{Clinical evaluation}

Detailed history was taken for the possible precipitating factors, peanut consumption (starting age and last consumption), duration of breast feeding, and family history of allergy. Patients were subjected to a general clinical examination, as well as chest, skin, and ENT examination to verify the diagnosis.

\section{Laboratory investigations}

Serum total IgE was measured by enzyme linked immunosorbent assay (Genzyme Diagnostics, Medix Biotech Inc, San Carlos, CA, USA). A serum IgE level was considered elevated if it exceeded the highest reference value for age [22]. The value used in correlation analysis was the percentage from the highest normal value for age (patient's actual value/highest normal value for age multiplied by 100)

Peanut Specific IgE was measured in children with positive peanut SPT results using the CLA allergenspecific IgE Assay according to the manufacturer's instructions (Hitachi Chemical Diagnostics, Mountain View, California 94043, USA). The concentration of $\geq 15 \mathrm{kUA} / \mathrm{L}$ was considered positive.

Complete blood counting was done using an automated cell counter (Coulter MicroDiff 18, Fullerton, CA, USA) and manual differential.

\section{Skin prick testing}

Skin prick test (SPT) was performed for each patient using a commercial peanut allergen extract, positive histamine control, and negative control (Omega Laboratories, Montréal, Canada). First generation short-acting antihistamines were avoided for at least 72 hours and second generation antihistamines were avoided for at least 5 days before testing. The test sites were marked and labeled at least three $\mathrm{cm}$ apart to avoid the overlapping of positive skin reactions. The marked site was dropped by the allergen and gently pricked by sterile skin test lancet. Positive and negative control solutions were similarly applied. The patient waited for at least 20 minutes before interpretation of the results. Largest and orthogonal diameters of any resultant wheal and flare were measured. A wheal diameter of $8 \mathrm{~mm}$ or greater was considered positive.

\section{Oral food challenge (OFC)}

Children with proven peanut sensitization were subjected to open oral peanut challenges under close medical observation taking all the precautions needed to treat anaphylaxis. A second informed consent was obtained from the parents or care-givers prior to the challenge. Children were given gradually increasing amounts of roasted peanuts at $30 \mathrm{~min}$ intervals and symptoms and physical signs were closely monitored. The total dose of peanut before considering that the challenge was negative was 15 grams of roasted whole peanuts. An open feeding of a larger portion (ageappropriate serving) followed negative challenges and then children were kept under observation for 2 more hours. The cases with negative challenges were supplied with a contact phone number to report any reactions that might develop within the next 24 hours while cases with positive challenge were treated and kept in hospital for 12-24 hours under observation. 


\section{Statistical analysis}

Data were analyzed by a standard computer program (SPSS version 13 for Windows, Chicago IL, USA). The mean, standard deviation (SD), median, and interquartile (IQ) range presented the descriptive data. Groups were compared using the students $\mathrm{t}$ - test for parametric and the Kruskal-Wallis and Mann- Whitney Z tests for nonparametric data. Fisher's Exact and Chi square $\left(\mathrm{X}^{2}\right)$ tests were used for comparison of categorical data. Pearson and Spearman coefficient tests were used to correlate the numeric data. For all tests, p values less than 0.05 were considered statistically significant.

\section{Results}

The studied sample comprised 55 boys and 45 girls. Their ages ranged between two and 10 years [median $(\mathrm{IQR})=6.28(4.0)$; mean $(\mathrm{SD})=6.51(2.35)$ years $]$. The duration of exclusive breast feeding ranged from 3 to 8 months [median $(\mathrm{IQR})=6.00(2.00)$; mean $(\mathrm{SD})=$ 5.42 (1.32) months] and the age of stoppage of breast feeding ranged from 9 to 24 months [median (IQR) = 16.00 (7.00); mean (SD) $=16.30$ (4.26) months]. None of the subjects gave a history suggestive of peanut allergy and all of them started consuming roasted peanuts before the age of two. The duration since last peanut consumption ranged between one and 15 days [median $(\mathrm{IQR})=4.00$ (3.00); mean $(\mathrm{SD})=4.63$ (8.94) days]. The diagnoses included bronchial asthma in 63 children, urticaria in 57, allergic rhinitis in 22, atopic dermatitis in five, and history of anaphylaxis due to unknown cause in one patient. Fifty six children had one, 40 had two, and four had three of the aforementioned allergic diseases.

Skin prick testing with peanut extract gave positive results (wheal diameter $\geq 8 \mathrm{~mm}$ ) in seven children (7\%). The specific IgE results of these children confirmed sensitization $[$ range $=17-24$; median $(\mathrm{IQR})=21.0(4.00)$; mean $(\mathrm{SD})=20.9(2.41) ; 95 \% \mathrm{CI}=16.9-24.5 \mathrm{kUA} / \mathrm{L}]$. Six out of the 7 peanut sensitized patients consented for an open oral challenge with roasted whole peanuts. Three out of the six children showed immediate allergic manifestations after consumption (two developed urticaria and respiratory manifestations and one developed urticaria only) and were thus proven to have allergy to peanut. The remaining three developed no symptoms or signs upon oral challenge with peanuts (Table 1). Neither the positive nor negative OFC cases developed late phase reactions to peanut. Two of the peanut allergic children were brothers (Table 1 ; patients 1 and 2). They had bronchial asthma and attacks of urticaria and the elder one also suffered from allergic rhinitis. The peanut specific IgE levels could not be correlated to any of the clinical or laboratory data of the sensitized children. Children with positive oral challenge were statistically comparable to those with negative results as far as their clinical and laboratory data are concerned.

Seventy percent of the studied sample gave a positive family history of allergy with no statistically significant relation to peanut sensitization. However, the 7 children sensitized to peanut had positive family history of allergic diseases. None of the subjects gave a history suggestive of peanut allergy in the family. Peanut SPT results did not vary according to gender. Positive results were obtained in 5 out of 55 boys and 2 out of 45 girls. Peanut sensitization rates were not influenced by the duration of exclusive breast feeding, age at complete weaning from the breast, last peanut consumption, serum total IgE level, or peripheral blood eosinophil count (Table 2).

The SPT results were not influenced by the target organ affected whether respiratory or cutaneous. Also, peanut sensitization did not vary according to the number of target organs affected in the studied sample $\left(X^{2}=2.714 ; \mathrm{p}=0.257\right)$. Ten children had confirmed allergy to other foods (egg allergy in two, fish in three, cow milk in two, sesame in one, banana in one, and prunes in one); 9 of them were not peanut sensitized while one was sensitized to peanut and allergic to bananas. The relation between peanut sensitization rates and the presence of other food allergies did not reach statistical significance $\left(\mathrm{X}^{2}=0.154 ; \mathrm{p}=0.695\right)$.

The wheal diameter of the peanut sensitized children was not correlated to age at complete weaning from the breast, days since last peanut consumption, days since last antihistamine consumption, serum total IgE, serum specific IgE, peripheral blood eosinophil count, or histamine wheal diameter.

\section{Discussion}

The frequency of peanut sensitization in our series was $7 \%$. The sensitized children were subjected to open oral challenges except for one child whose parents did not consent to the challenge due to a past history of anaphylaxis of unknown etiology. Only three patients were proven to be allergic to peanut by oral challenge giving a $3 \%$ rate of peanut allergy in the studied sample. The studied sample comprised children with physiciandiagnosed allergy and therefore does not represent the general population. The Peanut specific IgE was only estimated in the 7 children with positive SPT for confirmation of sensitization. It would be worthwhile to estimate its expression in children with negative SPT. However, this was not among the objectives of the current study.

Population based data from some other parts of the world show different rates of sensitization ranging between 3.3\% in England [4] and 4.6\% among children from the Netherlands [23]. Cross sectional random 
Table 1 Clinical and laboratory data of the peanut sensitized children

\begin{tabular}{|c|c|c|c|c|c|c|c|c|c|c|c|c|c|}
\hline $\bar{n}$ & Sex & $\begin{array}{c}\text { Age } \\
\text { (yr) }\end{array}$ & $\begin{array}{l}\text { FH of } \\
\text { allergy }\end{array}$ & $\begin{array}{l}\text { BF only } \\
\text { (mo) }\end{array}$ & $\begin{array}{c}\text { BF } \\
\text { stopped } \\
\text { (mo) }\end{array}$ & $\begin{array}{l}\text { Allergy manifestations } \\
\text { (target organs) }\end{array}$ & $\begin{array}{l}\text { Other food } \\
\text { allergy }\end{array}$ & $\begin{array}{l}\text { Wheal } \\
(\mathrm{mm})\end{array}$ & $\begin{array}{l}\text { Flare } \\
(\mathrm{mm})\end{array}$ & $\begin{array}{c}\text { Total lgE } \\
(\mathrm{kUA} / \mathrm{l})\end{array}$ & $\begin{array}{l}\text { Specific lgE } \\
(k \cup A / l)\end{array}$ & $\begin{array}{c}\mathrm{AEC} \\
\left(/ \mathrm{mm}^{3}\right)\end{array}$ & $\begin{array}{l}\text { OFC } \\
\text { test }\end{array}$ \\
\hline 1 & M & 9 & + & 6 & 15 & AR - BA - Urticaria & - & 10 & 20 & 221 & 23 & 300 & + \\
\hline 2 & M & 7 & + & 4 & 18 & BA - Urticaria & - & 9 & 18 & 76 & 20 & 120 & + \\
\hline 3 & M & 9 & + & 6 & 15 & BA - Urticaria & - & 9 & 18 & 130 & 24 & 100 & + \\
\hline 4 & $\mathrm{~F}$ & 9 & + & 5 & 12 & AD - Urticaria & - & 9 & 18 & 115 & 22 & 240 & - \\
\hline 5 & M & 9 & + & 6 & 12 & AR - BA - Urticaria & - & 9 & 19 & 266 & 19 & 300 & - \\
\hline 6 & $M$ & 5 & + & 4 & 16 & AD - Anaphylaxis & - & 8 & 16 & 85 & 17 & 80 & ND \\
\hline 7 & $\mathrm{~F}$ & 5 & + & 7 & 13 & Urticaria & + & 9 & 20 & 212 & 21 & 70 & - \\
\hline
\end{tabular}

AD: atopic dermatitis; AR: allergic rhinitis; AEC: absolute eosinophil count; BA: bronchial asthma; BF: breast feeding; F: female; FH: family history; M: male; ND: not done; OFC: oral food challenge.

telephone surveys revealed self reported peanut allergy in $0.6-1.4 \%$ in the US $[2,3], 0.93-1 \%$ in Canada, and $1.5 \%$ in the UK [12]. The prevalence of peanut allergy is relatively low in Asian children (0.43\% - 0.64\%) [24].

We considered a SPT wheal size of $8 \mathrm{~mm}$ and specific IgE level of $15 \mathrm{kUA} / \mathrm{L}$ as our cut off values for predicting peanut allergy $[17,25]$. Nevertheless, only half of the sensitized children had clinical reactions upon oral challenge. We performed an oral challenge despite the fact that our cut off values may diagnose peanut allergy because none of the sensitized subjects gave a history suggestive of peanut allergy. It seems that the cut off values should be tailored to the levels of consumption in different geographical locations. A recent study from the UK reported a $22.4 \%$ prevalence of clinical peanut allergy among sensitized subjects. The authors used the same wheal diameter and specific IgE cut off values that we used [25]. The published peanut specific IgE cut off values are variable ranging between 5 up to $57 \mathrm{kUA} / \mathrm{L}$ [26,27]. A wheal diameter of $16 \mathrm{~mm}$ was considered to have a positive predictive value of $100 \%$ for allergy to peanuts [27].

Although a prior probability from the history is an important starting point in the diagnosis of peanut allergy, none of our subjects gave a history suggestive of peanut allergy and all of them started consuming roasted peanuts before the age of 2 years. Roasted peanut is a popular snack in Egypt and its allergy is not a public concern due to underestimation of its significance even from the health care workers' point of view. The history was reported to be notoriously poor (approximately $30 \%$ verified) in identifying causal foods for chronic disorders such as atopic dermatitis [16]. The early peanut consumption by children does not seem to be a risk factor for peanut allergy and was postulated to be even protective [28].

There was no significant relation between the duration of breast feeding and peanut sensitization in the current study. A relevant study noted that neither the maternal peanut consumption during pregnancy and lactation nor the duration of breast feeding was associated with the development of peanut allergy [29]. On the other hand, a recent case-control study assumed that exposure to peanut allergens in utero or through breast milk may increase the risk of developing peanut allergy [30].

A family history of atopy, especially of food allergy, is a good screening test to identify an individual at risk of food allergy and the rate of allergy in a sibling of an

Table 2 Variation of some clinical and laboratory data according to peanut sensitization*

\begin{tabular}{|c|c|c|c|c|}
\hline Variable & Peanut $+(n=7)$ & Peanut - $(n=93)$ & Test & $p$ value \\
\hline Age (yr) - median (IQR) & $9.0(4.00)$ & $6.0(4.75)$ & $Z=-0.225$ & 0.221 \\
\hline Gender (male/female) & $05 / 02$ & $50 / 43$ & $X^{2}=0.821$ & 0.365 \\
\hline Positive family history of allergy (\%) & $100 \%$ & $75.3 \%$ & $X^{2}=2.248$ & 0.134 \\
\hline Exclusive BF duration (mo) - median (IQR) & $6.0(2.0)$ & $6.0(2.0)$ & $Z=-0.071$ & 0.943 \\
\hline Age of BF stoppage (mo) - median (IQR) & $15.0(4.0)$ & $16.0(6.0)$ & $Z=-1.211$ & 0.226 \\
\hline Last peanut consumption (days) - median (IQR) & $5.0(2.0)$ & $4.0(3.0)$ & $Z=-0.807$ & 0.420 \\
\hline Last antihistamine consumption (days) - median (IQR) & $6.0(3.0)$ & $5.0(4.0)$ & $Z=-1.096$ & 0.273 \\
\hline$\overline{\mathrm{AEC}}\left(\right.$ cells $\left./ \mathrm{mm}^{3}\right)$ - median (IQR) & $120.0(220.0)$ & $90.0(62.5)$ & $Z=-1.935$ & 0.053 \\
\hline Total lqE (kUA/L) - median (IOR) & $130.0(136.0)$ & $113.0(50.0)$ & $Z=-1.008$ & 0.313 \\
\hline
\end{tabular}

AEC: absolute eosinophil count; BF: breast feeding; IQR: interquartile range; Peanut +: peanut sensitive; Peanut -: not sensitized to peanut.

* Peanut sensitization: SPT wheal diameter $\geq 8$ and specific lgE $\geq 15 \mathrm{kUA} / \mathrm{L}$ 
allergic person is known to be higher than the rate in the general population. Although we could not demonstrate a statistically significant relation between the family history of allergy and peanut sensitization, all peanut sensitive children came from atopic families. Also, two of the peanut allergic children were brothers. The current study did not demonstrate a significant gender difference in peanut sensitization but the boys outnumbered girls in the whole sample. Higher prevalence of peanut allergy among male children was previously reported [31].

The peanut sensitization in the present study did not vary according to the site of allergy. However, the 7 peanut sensitized children had physician diagnosed skin allergy combined with respiratory allergy in five. A relevant study on Asian children revealed that most (89.5\%) of first reactions featured skin changes and that respiratory and GI symptoms did not occur as the sole manifestation [32]. One child with positive oral challenge in our series had allergy in one target-organ (skin) and a past history of one attack of unexplained anaphylaxis and two children had symptoms in more than one system (skin and respiratory). According to a voluntary registry in the Isle of Wight, about half of all children with peanut allergy had allergic manifestations in one target-organ system, $30 \%$ in two, $10 \%-15 \%$ in three, and $1 \%$ had symptoms in four systems [33].

Self-reported food allergy is an independent risk factor for potentially fatal childhood asthma [34]. Peanut allergy was reported in $28.8 \%$ of children with asthma in a recent investigation [35]. One of our peanut sensitized children was allergic to bananas. Her peanut oral challenge yielded a negative result. The girl was not latex sensitive and the parents did not consent to any further investigations. Evaluation of pollen cross reactivity would have been worthwhile [36].

From this pilot study, it seems that peanut allergy in Egypt is underestimated and that the sensitization rates are even higher. Skin prick and specific IgE testing aided by history are good screening tools to determine candidates for peanut oral food challenge. Peanut allergy can be associated with any clinical form of allergy and the causal relationship needs extensive evaluation. The conclusions are limited by the sample size and study design which targeted physician-diagnosed allergy rather than the general population. Further wider-scale populationbased studies as well as a national registry are needed to be able to outline the real magnitude of peanut allergy and its clinical correlates in our country.

\section{Author details}

'Departments of Pediatrics, Ain Shams University, Ramses Street, Cairo 11566, Egypt. ${ }^{2}$ Department of Clinical Pathology, Ain Shams University, Ramses
Street, Cairo 11566, Egypt. ${ }^{3}$ Allergy/Immunology Unit, VACSERA, Cairo 12311 , Egypt.

\section{Authors' contributions}

EH put the study design and coordination, performed the statistical analysis, and drafted the manuscript. GG participated in collection of the study sample and data analysis. AS performed the total and specific lgE assay and differential blood cell counting. AE collected the study sample and performed the skin prick test. All authors read and approved the final manuscript.

\section{Competing interests}

The authors declare that they have no competing interests.

Received: 29 October 2010 Accepted: 31 May 2011

Published: 31 May 2011

\section{References}

1. Sicherer SH, Munoz-Furlong A, Sampson HA: Prevalence of peanut and tree nut allergy in the United States determined by means of a random digit dial telephone survey: a 5-year follow-up study. J Allergy Clin Immunol 2003, 112(6):1203-1207.

2. Sicherer SH, Munoz-Furlong A, Burks AW, Sampson HA: Prevalence of peanut and tree nut allergy in the US determined by a random digit dial telephone survey. J Allergy Clin Immunol 1999, 103(4):559-562.

3. Sicherer SH, Muñoz-Furlong A, Godbold JH, Sampson HA: US prevalence of self-reported peanut, tree nut, and sesame allergy: 11-year follow-up. J Allergy Clin Immunol 2010, 125(6):1322-1326.

4. Grundy J, Matthews S, Bateman B, Dean T, Arshad SH: Rising prevalence of allergy to peanut in children: data from 2 sequential cohorts. J Allergy Clin Immunol 2002, 110(5):784-789.

5. Kagan RS, Joseph L, Dufresne C, Gray-Donald K, Turnbull E, Pierre YS, Clarke AE: Prevalence of peanut allergy in primary-school children in Montreal, Canada. J Allergy Clin Immunol 2003, 112(6):1223-1228.

6. Mullins RJ, Dear KB, Tang ML: Characteristics of childhood peanut allergy in the Australian Capital Territory, 1995 to 2007. J Allergy Clin Immunol 2009, 123(3):689-693.

7. Chiang WC, Kidon MI, Liew WK, Goh A, Tang JP, Chay OM: The changing face of food hypersensitivity in an Asian community. Clin Exp Allergy 2007, 37(7):1055-1061.

8. Sicherer SH, Sampson HA: Peanut allergy: emerging concepts and approaches for an apparent epidemic. J Allergy Clin Immunol 2007, 120(3):491-503.

9. Lack G: Epidemiologic risks for food allergy. J Allergy Clin Immunol 2008, 121(6):1331-1336.

10. Sampson HA: Clinical practice. Peanut allergy. N Engl J Med 2002, 346(17):1294-1299

11. Al-Ahmed N, Alsowaidi S, Vadas P: Peanut allergy: an overview. Allergy Asthma Clin Immunol 2008, 4(4):139-143.

12. Ben-Shoshan M, Harrington DW, Soller L, Fragapane J, Joseph L, St Pierre $Y$, Godefroy SB, Elliott SJ, Clarke AE: A population-based study on peanut, tree nut, fish, shellfish, and sesame allergy prevalence in Canada. J Allergy Clin Immunol 2010, 125(6):1322-1326.

13. Rona RJ, Keil T, Summers C, Gislason D, Zuidmeer L, Sodergren E, Sigurdardottir ST, Lindner T, Goldhahn K, Dahlstrom J, McBride D, Madsen C: The prevalence of food allergy: a meta-analysis. J Allergy Clin Immunol 2007, 120(3):638-646.

14. Du Toit G, Santos A, Roberts G, Fox AT, Smith P, Lack G: The diagnosis of IgE-mediated food allergy in childhood. Pediatr Allergy Immunol 2009, 20(4):309-319.

15. Sampson HA, Ho DG: Relationship between food-specific IgE concentrations and the risk of positive food challenges in children and adolescents. J Allergy Clin Immunol 1997, 100(4):444-451.

16. Sampson HA, Albergo R: Comparison of results of skin tests, RAST, and double blinded placebo-controlled food challenges in children with atopic dermatitis. J Allergy Clin Immunol 1984, 74(1):26-33.

17. Bahna SL: Reflections on current food allergy controversies: specific lgE test application, patch testing, eosinophilic esophagitis, and probiotics. Allergy Asthma Proc 2008, 29(5):447-452.

18. Roberts $G$, Lack G: Diagnosing peanut allergy with skin prick and specific IgE testing. J Allergy Clin Immunol 2005, 115(6):1291-1296. 
19. Sampson HA: Utility of food-specific lgE concentrations in predicting symptomatic food allergy. J Allergy Clin Immunol 2001, 107(5):891-896.

20. Sicherer SH, Sampson HA: Food allergy. J Allergy Clin Immunol 2010, 125(2 Suppl 2):S116-125

21. Wainstein BK, Yee A, Jelley D, Ziegler M, Ziegler JB: Combining skin prick, immediate skin application and specific-lgE testing in the diagnosis of peanut allergy in children. Pediatr Allergy Immunol 2007, 18(3):231-9.

22. Geaghan SM: Normal blood values: selected reference values for neonatal, pediatric and adult populations. In Hematology basic principles and practice.. 3 edition. Edited by: Hoffman R, Benz EJ, Shattil SJ, Furie B, Cohen HJ, et al. Philadelphia: Churchill Livingstone; 2000:2520-2528.

23. de Jong AB, Dikkeschei LD, Brand PL: Sensitization patterns to food and inhalant allergens in childhood: a comparison of non-sensitized, monosensitized, and polysensitized children. Pediatr Allergy Immunol 2010, 22(2):166-71.

24. Shek LP, Cabrera-Morales EA, Soh SE, Gerez I, Ng PZ, Yi FC, Ma S, Lee BW: A population-based questionnaire survey on the prevalence of peanut, tree nut, and shellfish allergy in 2 Asian populations. J Allergy Clin Immunol 2010, 126(2):324-331.

25. Nicolaou N, Poorafshar M, Murray C, Simpson A, Winell H, Kerry G, Härlin A, Woodcock A, Ahlstedt S, Custovic A: Allergy or tolerance in children sensitized to peanut: prevalence and differentiation using componentresolved diagnostics. J Allergy Clin Immunol 2010, 125(1):191-197.

26. Perry TT, Matsui EC, Kay Conover-Walker M, Wood RA: The relationship of allergen-specific IgE levels and oral food challenge outcome. J Allergy Clin Immunol 2004, 114(1):144-149.

27. Rancé $F$, Abbal $M$, Lauwers-Cancès $V:$ Improved screening for peanut allergy by the combined use of skin prick tests and specific IgE assays. $J$ Allergy Clin Immunol 2002, 109(6):1027-1033.

28. Du Toit G, Katz Y, Sasieni P, Mesher D, Maleki SJ, Fisher HR, Fox AT, Turcanu V, Amir T, Zadik-Mnuhin G, Cohen A, Livne I, Lack G: Early consumption of peanuts in infancy is associated with a low prevalence of peanut allergy. J Allergy Clin Immunol 2008, 122(5):984-991.

29. Lack G, Fox D, Northstone K, Golding J: Factors associated with the development of peanut allergy in childhood. N Engl J Med 2003, 348(11):977-985

30. DesRoches, Infante-Rivard C, Paradis L, Paradis J, Haddad E: Peanut allergy: is maternal transmission of antigens during pregnancy and breastfeeding a risk factor? I Investig Allergol Clin Immunol 2010, 20(4):289-294.

31. Tariq SM, Stevens M, Matthews S, Ridout S, Twiselton R, Hide DW: Cohort study of peanut and tree nut sensitization by age of 4 years. BMJ 1996 313(7056):514-517.

32. Chiang WC, Pons L, Kidon MI, Liew WK, Goh A, Wesley Burks A: Serological and clinical characteristics of children with peanut sensitization in an Asian community. Pediatr Allergy Immunol 2010, 21(2 Pt 2):e429-38.

33. Al-Muhsen S, Clarke AE, Kagan RS: Peanut allergy: an overview. CMAJ 2003, 168(10):1279-1285

34. Vogel NM, Katz HT, Lopez R, Lang DM: Food allergy is associated with potentially fatal childhood asthma. J Asthma 2008, 45(10):862-866.

35. Simpson AB, Yousef $E$, Hossain J: Association between peanut allergy and asthma morbidity. J Pediatr 2010, 156(5):777-781.

36. Miralles JC, Caravaca F, Guillén F, Lombardero M, Negro JM: Cross-reactivity between Platanus pollen and vegetables. Allergy 2002, 57(2):146-149.

doi:10.1186/1710-1492-7-11

Cite this article as: Hossny et al:: Peanut sensitization in a group of allergic Egyptian children. Allergy, Asthma \& Clinical Immunology 2011 7:11.

\section{Submit your next manuscript to BioMed Central and take full advantage of:}

- Convenient online submission

- Thorough peer review

- No space constraints or color figure charges

- Immediate publication on acceptance

- Inclusion in PubMed, CAS, Scopus and Google Scholar

- Research which is freely available for redistribution 